\title{
Sulfosulfuron Incorporated in Micelles Adsorbed on Montmorillonite for Slow Release Formulations
}

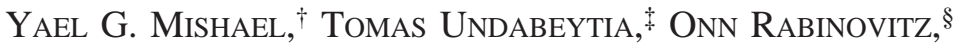 \\ BARUCH RUbin, ${ }^{\S}$ AND SHLOMO NIR*,†
}

\begin{abstract}
Seagram Center for Soil and Water Sciences, Faculty of Agricultural, Food, and Environmental Sciences, Hebrew University of Jerusalem, Rehovot 76100, Israel, Instituto de Recursos Naturales y Agrobiologia, CSIC, Sevilla, Spain, and Department of Field Crops, Vegetables, and Genetics, Faculty of Agricultural, Food, and Environmental Sciences, Hebrew University of Jerusalem, Israel
\end{abstract}

\begin{abstract}
Slow release formulations of the anionic herbicide sulfosulfuron (SFS) were prepared by incorporating it in micelles of an organic cation octadecyltrimethylammonium, which adsorb on the clay-mineral montmorillonite. The fraction of SFS adsorbed on the micelle-clay complex reached $98 \%$, whereas for monomer-clay complexes, its adsorption was insignificant. Fluorescence studies showed surface contact between the micelles and the clay surface. The rate of SFS release from the micelle-clay formulations in aqueous suspensions was slow $(<1 \%, 72 \mathrm{~h})$. Spraying SFS formulations on a thin soil layer in a funnel, followed by irrigations $(50 \mathrm{~mm})$, resulted in complete elution of SFS from the commercial formulation (dispersible granular) versus $4 \%$ from the micelle-clay formulation. A plant bioassay in Rehovot soil showed that these respective formulations yielded 23 and $65 \%$ of shoot growth inhibition of foxtail. Consequently, the slow release micelle-clay formulations of SFS yield significantly reduced leaching and enhanced biological activity, thus providing environmental and agricultural advantages.
\end{abstract}

KEYWORDS: Octadecyltrimethylammonium; micelles; montmorillonite; fluorescence; sulfosulfuron; slow release; soil column; bioassay

\section{INTRODUCTION}

The sulfonylurea herbicide sulfosulfuron (SFS) is active at very low doses in inhibiting one of the early steps in the biosynthesis of branched amino acids in plants. Sulfonylurea herbicides, which are weak acids, are negatively charged at moderately basic $\mathrm{pH}$, and their solubility in water increases with $\mathrm{pH}(1)$. A severe problem encountered in soils with a basic $\mathrm{pH}$ is leaching of the herbicide molecules to deep soil layers and migration to nontarget areas $(2-6)$. These factors reduce the herbicidal efficacy, causing an increase in frequency and dose of herbicide application, which increases the ecological contamination and cost.

In an attempt to solve this problem, clay based formulations have been designed (7). The adsorption of alkylammonium cations on clay minerals has been widely studied $(8-12)$. Binding of organic pollutants from soils or water to surfactant has been used for several environmental applications. The surfactant can alter the pollutant's transport properties, stabilize it, or increase its solubility for further water or soil purification $(13-16)$

* Corresponding author. E-mail: nir1@agri.huji.ac.il. Fax: 972-89475181. Phone: 972-8-9489172.

Seagram Center for Soil and Water Sciences.

$\div$ CSIC.

$\S$ Department of Field Crops, Vegetables, and Genetics.
The current work presents new designed slow-release formulations of the anionic herbicide, SFS, for reducing its leaching. These formulations are based on utilizing two characteristics of octadecyltrimethylammonium (ODTMA) positively charged micelles: (i) their affinity to incorporate the anionic herbicide and (ii) their high adsorption on a negatively charged clay-mineral, montmorillonite.

We have recently characterized the micelle-clay system by combining freeze fracture electron microscopy, X-ray diffraction, and adsorption measurements. An important outcome emerged that the (ODTMA)micelle-clay complex has different characteristics from those of the complex obtained by adsorption of ODTMA monomers on montmorillonite at a loading below or above the cation exchange capacity (CEC). Only the micelleclay complex yielded large fractions of adsorbed sulfometuron (SFM), which also required optimization of the ratios between the clay and ODTMA (17). This issue was further tested with SFS. The current studies also supplement the characterization of the micelle-clay system by fluorescence measurements. The effect of different sequences of addition of the components of the formulations was tested to gain more understanding of the characteristics of the anionic herbicide-micelle-clay system and also to test its future potential in removing anionic organic pollutants from water. 


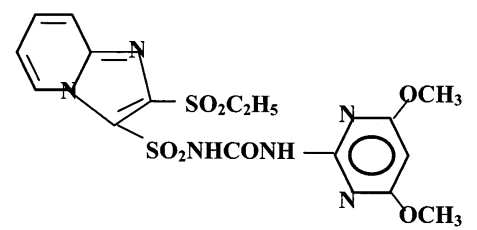

Figure 1. Sulfosulfuron: molecular structure.

Tests of slow release of SFS from its formulations and its leaching were conducted by several methods: 1 . Release in aqueous suspensions 2 . Release by distributing the formulation on a thin soil layer placed in a funnel and irrigating. This new method has a potential for future tests of correlations between release and leaching 3 . Release and leaching by spraying the formulation on a soil column extensively irrigated (brakethrough curve). 4. Leaching in soil columns tested by a bioassay, which is a stage prior to field experiments. We will show that the designed SFS-micelle-clay formulations reduce herbicide leaching and increase its biological activity in comparison with the commercial formulation (MONITOR, dispersible granular).

\section{MATERIALS AND METHODS}

Materials. The clay used was Wyoming $\mathrm{Na}-$ montmorillonite ( $\mathrm{SWy}$ 2) obtained from the Source Clays Repository of The Clay Minerals Society (Columbia, MO) (cation exchange capacity $0.8 \mathrm{mmol} / \mathrm{g}$ ). ODTMA (critical micelle concentration (CMC), $0.3 \mathrm{mM}$ ), Triton-X 100 , and the buffers trizma $\mathrm{HCl}$ and trizma base were purchased from Sigma-Aldrich (Sigma Chemical Co. St. Louis, MO). N-NBD-PE, 1,2Dipalmitoyl-sn-Glycero-3-Phosphoethanolamine-N-(7-nitro-2-1,3benzoxadiazol-4-yl) was purchased from Avanti (Avanti polar-lipids, INC. Alabaster, AL). Rhodamin B (RhB), HPLC acetonitrile, and water were purchased from Merck (Darmstadt, Germany). Sulfosulfuron, 1-(4,6-dimethylpyrimidin-2-yl)-3-(2-ethylsulfonylimidazo [1,2-a] pyridin-3-yl) (analytical grade, $\mathrm{p} K_{\mathrm{a}}=3.5$, solubility in water $17.6 \mathrm{mg} / \mathrm{L}$ at $\mathrm{pH} 5$ and $1626.8 \mathrm{mg} / \mathrm{L}$ at $\mathrm{pH} 7$ ) and a commercial formulation (MONITOR 75\% ai, dispersible granular) were obtained from E. I. Du Pont de Nemours and Company (Wilmington, DE). Dialysis bags made of regenerated cellulose $1000 \mathrm{D}$ were obtained from Bio Lab LTD (Jerusalem, Israel). The structural formula of the herbicide is shown in Figure 1.

A soil from Seville was used for a soil column test and a soil from Rehovot was used for a plant bioassay. The upper layer $(20 \mathrm{~cm})$ of a Typical Xeropsamment soil from Coria, Sevilla, Spain was used, after being dried and passed through a $2 \mathrm{~mm}$ sieve. Its characteristics are: $\mathrm{pH} 8.0$, carbonate content $6.9 \%$, organic matter content $0.92 \%$, sand $87.5 \%$, silt $4 \%$ and clay $8.4 \%$. The Rehovot soil was collected from the top $30 \mathrm{~cm}$ of a sandy loam soil at the Faculty's Experimental Farm in Rehovot, Israel, air-dried, and sieved through a $2 \mathrm{~mm}$ screen. The $\mathrm{pH}$ of the soil is 7.5 , carbonate content $0.0 \%$, organic matter content $0.2 \%$, sand $95.5 \%$, silt $3.3 \%$ and clay $1.2 \%$ (18). Green foxtail (Setaria viridis L. Beauvios) and Sorghum (Sorghum bicolor R. S.-610) were used as a test plants (Hazera-Quality Seeds, Israel).

Methods. SFS Incorporation in Micelles. All solutions of SFS were prepared in a buffer solution, $0.05 \mathrm{M},(\mathrm{pH} 7.4)$ of tris $\mathrm{HCl}(6.61 \mathrm{~g} / \mathrm{L})$ and tris base $(0.97 \mathrm{~g} / \mathrm{L})$. An additional buffer, sodium tetraborate-10hydrate with $\mathrm{HCl}$, was tested, and there was no difference in the results indicating that the Tris buffer does not disrupt the system. SFS and ODTMA solutions were prepared by first adding SFS to the buffer solution and then adding the desired amount of ODTMA. Dialysis bags containing $20 \mathrm{~mL}$ of a solution of SFS and ODTMA were added to 40 $\mathrm{mL}$ of the buffer solution in centrifuge tubes. The tubes were kept under continuous agitation for 3 days, reaching equilibration. SFS concentrations were measured inside and outside the dialysis bag to determine the percent of SFS bound to micelles and in solution.

For SFS analysis, all supernatants were filtered with Teflon filters (Pall Corporation, MI) of $0.2 \mu \mathrm{m}$ pore diameter. SFS was analyzed by HPLC (Merck Hitachi 6200, Tokyo, Japan) equipped with photodiode array detector set at a wavelength of $216 \mathrm{~nm}$. The reverse phase column was LiChrospher 100 RP-18 (5 mM) (Merck, Darmstadt, Germany). The mobile phase was $70 \%$ acetonitrile and $30 \%$ acidified water (trifluoroacetic acid, $\mathrm{pH}=3$ ). The flow rate was $1.0 \mathrm{~mL} \mathrm{~min}{ }^{-1}$ (17). The retention time was $3 \mathrm{~min}$. The presence of the cations did not cause any interference with SFS detection.

SFS Speciation and Adsorption on Clay with Micelles. All solutions of SFS were prepared in the buffer solution ( $\mathrm{pH}$ 7.4). Dialysis bags containing $20 \mathrm{~mL}$ of SFS and ODTMA were added to $40 \mathrm{~mL}$ of the buffer solution in centrifuge tubes. The tubes were kept under continuous agitation for 3 days, reaching equilibration. To measure SFS adsorption on the clay-mineral in the presence of micelles, the claymineral was added inside the dialysis bags. To measure SFS adsorption on clay without micelles, the clay mineral was added outside the dialysis bags. The herbicide is in one of three states: freely dissolved in solution, incorporated in micelles, and adsorbed by the clay-micelle complex. The concentration of the first is known from the external solution analysis, the second from the internal solution after separation of the clay, and the third by mass balance. In both cases, SFS concentrations were measured inside and outside the dialysis bag to determine the percent of SFS bound to micelles, adsorbed on clay and in solution. The samples containing clay were filtered, or centrifuged (at $15000 \mathrm{~g}$ for $30 \mathrm{~min}$ ) when the clay concentration was too high to enable filtering, to separate the clay from the supernatant. The concentration of SFS adsorbed on the clay was deduced by knowing the total amount of SFS added to the system (17).

Preparation of SFS-ODTMA-Montmorillonite Formulations. All solutions of SFS were prepared in the buffer solution ( $\mathrm{pH}$ 7.4). Solutions of SFS and ODTMA $(10 \mathrm{~mL})$ were added to clay $(5 \mathrm{~mL})$ in $40 \mathrm{~mL}$ polycarbonate centrifuge tubes, reaching a final volume of $15 \mathrm{~mL}$. The final concentrations were $0.25-1 \mathrm{mM}$ SFS, $5 \mathrm{mM}$ of ODTMA, and 5 $\mathrm{g}$ clay/L. Three other procedures of preparation were tested: (i) adding the clay, ODTMA, and SFS all together; (ii) adding ODTMA to the clay, and after $24 \mathrm{~h}$ adding SFS; and (iii) adding SFS to the clay, and after $24 \mathrm{~h}$ adding ODTMA. In all cases, the suspensions were kept under continuous agitation for 3 days, reaching equilibration. Supernatants were separated by centrifugation at $15000 \mathrm{~g}$ for $30 \mathrm{~min}$, and SFS was analyzed as described above. The formulations were designated according to the added components concentrations, herbicide/cation/ clay (Table 3).

Fluorescence Measurements. A solution of ODTMA micelles, which included a fluorescent probe, $\mathrm{N}-\mathrm{NBD}-\mathrm{PE}$, was prepared by adding 2 $\mathrm{mg}$ of $\mathrm{N}-\mathrm{NBD}-\mathrm{PE}$ to $100 \mathrm{~mL}$ of a $7.5 \mathrm{mM}$ ODTMA solution, reaching a ratio of about $1 / 100(\mathrm{w} / \mathrm{w})$. The fluorescence intensity of the micelle $-\mathrm{N}-\mathrm{NBD}-\mathrm{PE}$ solution increased linearly $(1.875-7.5 \mathrm{mM}$ ODTMA). Three clay suspensions, 3, 5, and $10 \mathrm{~g} / \mathrm{L}$, were loaded up to $2.5 \%$ of the CEC with a fluorescent probe, RhB. Different ODTMAclay complexes were prepared with or without both probes. The intensity measured for the control nonlabeled complexes and supernatant, which is due to light scattering, was subtracted from that of labeled ones. The fluorescence intensity of the different complexes and of the supernatant was measured in a Cary Eclipse fluorometer (Varian, ISI, Melbourne, Australia) at excitation and emission wavelengths of 465 and $530 \mathrm{~nm}$, respectively. The fluorescence intensity of the supernatant was also determined by addition of Triton X-100 (2\% w/w), which yielded a significant intensity increase, due to reduction in selfquenching upon probe dilutions.

Dialysis bags containing $20 \mathrm{~mL}$ of an ODTMA solution $(7.5 \mathrm{mM})$, including $\mathrm{N}-\mathrm{NBD}-\mathrm{PE}$, were added to $40 \mathrm{~mL}$ of water in centrifuge tubes to determine $\mathrm{N}-\mathrm{NBD}-\mathrm{PE}$ exchange to water. Dialysis bags containing $20 \mathrm{~mL}$ of an ODTMA solution $(0.25 \mathrm{mM})$, including $\mathrm{N}-\mathrm{NBD}-\mathrm{PE}$, were added to $40 \mathrm{~mL}$ of a clay suspension $(0.5 \mathrm{~g} / \mathrm{L})$ in centrifuge tubes to determine $\mathrm{N}-\mathrm{NBD}-\mathrm{PE}$ exchange to the claymineral. Some exchange was expected to occur due to monomer adsorption on the clay when added outside the dialysis bag (see below). The tubes were kept under continuous agitation for 2 days. N-NBDPE fluorescence intensities were measured inside and outside the dialysis bag to determine the exchange.

SFS Desorption from Micelle-Clay Formulations. SFS desorption from micelle-clay formulations $5 / 5 / 0.5$ and $5 / 5 / 1$ in water was detected after incubation times varying from $10 \mathrm{~min}$ to $72 \mathrm{~h}$ at different clay concentrations. The formulations were added to $1 \mathrm{~L}$ of water in cups 
stirred constantly (by beaters as in a kitchen mixer), which were in a temperature-controlled bath. At the desired time, samples of $2 \mathrm{~mL}$ were taken from the cups by a syringe. The experiment was repeated by using magnetic stirrers and separating the clay from the supernatant in the samples taken (to avoid additional desorption after the samples were taken). There was no significant difference in the percent of SFS desorbed between the two procedures. The desorbed SFS was analyzed as described above.

Leaching Studies. Thin Soil Layers in Funnels-Analytical Test. The SFS-micelle-clay formulation $(5 / 5 / 0.5)$ and the commercial formulation were sprayed at a rate of $18 \mathrm{Kg}$ ai/ha on a very thin layer $(\sim 0.5 \mathrm{~cm})$ of a sandy loam Rehovot soil deposited on filter paper inside a Buchner funnel (10 cm diameter). The funnels were carefully irrigated with $50 \mathrm{~mm}$ of water by adding $5 \mathrm{~mm}$ every $10 \mathrm{~min}$. The leachates were collected after each irrigation and the leached herbicide concentration was determined analytically by HPLC.

Soil Columns-Analytical Test. Columns $28 \mathrm{~cm}$ long were constructed of methacrylate tubes of $3.0 \mathrm{~cm}$ diameter. The columns were covered at one end with a $1 \mathrm{~mm}$ nylon screen padded with a thin layer of glass wool $(0.5 \mathrm{~g})$ to hold the soil firmly in the column. The soil $(0.246 \mathrm{~kg})$ was packed from the top of the column creating a $24 \mathrm{~cm}$ soil column. A thin layer of glass wool was placed on top of the soil column to maintain a homogeneous surface during the irrigation.

In a preliminary experiment, two soil columns were saturated with distilled water to obtain moisture content of the soil column of $100 \%$ of the soil capacity. The difference between the weight of the saturated soil column and its dry weight gave a value of $57 \mathrm{~mL}$ for 1 pore volume.

The columns were equilibrated for $24 \mathrm{~h}$ with 1 pore volume of a $0.01 \mathrm{M} \mathrm{Ca}\left(\mathrm{NO}_{3}\right)_{2}$ solution, repeating this treatment for 4 days, and then followed by 1 pore volume of distilled water before spraying 10 $\mathrm{mL}$ of the commercial and micelle-clay formulations of SFS at a 420 $\mathrm{g}$ ai/ha dose. A new thin cover of glass wool was settled on top of each column, and distilled water equivalent to a half pore volume of the soil column was added every hour at the top of the column; the leachate collected was analyzed for SFS. The leaching experiments were done in triplicate for each formulation.

Plant Bioassay. Tin columns, with an upper exposed surface of 100 $\mathrm{cm}^{2}$ and $20 \mathrm{~cm}$ long, were filled with a sandy loam Rehovot soil. The column surface was sprayed with the SFS - micelle-clay formulations, the commercial formulation and with water (control) at a rate of $50 \mathrm{~g}$ ai/ha. The columns were carefully irrigated with $500 \mathrm{~m}^{3}$ water/ha (a total of $500 \mathrm{~mL}$ per column), adding $50 \mathrm{~mL}$ every $10 \mathrm{~min}$. This irrigation level was selected to ensure water movement up to $20 \mathrm{~cm}$ depth. Two columns of each treatment were sown with the test plant green foxtail (Setaria viridis L. Beauvios). After 16 days, the shoot growth and dry and wet weights were measured.

Four columns of each treatment were left for $24 \mathrm{~h}$ for equilibration and then sliced along their length to obtain two pots. Each pot was sliced into segments representing different soil depth $(0-5,5-10,10-$ 15 , and $15-20 \mathrm{~cm})$. Four Petri dishes were filled with the soil from each slice. To stay in the range of sensitivity of the plants $(0.1-2 \mathrm{ppb})$ the depth of 15-20 cm was diluted 10 times. Five seeds of sorghum were placed on the soil in each Petri dish. The plates were sealed and held tilted $\left(60^{\circ}\right)$ in the dark. After 5 days, the root length was measured. The percent of root growth inhibition was calculated by comparing the root length of each sample to the average length of the roots from the control columns.

Data Analysis. The leaching depths of the different formulations through the soil columns were subjected to analysis of variance and the main effects and interactions were tested for significance using repeated measures ANOVA. The means of effects of different formulations were compared by Student's $t$ test $(a=0.05)$, following one way ANOVA.

\section{RESULTS AND DISCUSSION}

SFS Incorporation in Micelles. To evaluate the affinity of the negatively charged herbicide to the positively charged micelles, the herbicide and cation were placed in dialysis bags at different concentrations. The percent of SFS bound to micelles
Table 1. SFS Incorporation in Micelles (\%)

\begin{tabular}{|c|c|c|}
\hline ODTMA (mM) & herbicide (mM) & $\begin{array}{l}\text { SFS bound to } \\
\text { micelles }(\%)^{a}\end{array}$ \\
\hline 0.1 & 0.01 & \\
\hline 2.5 & 0.125 & 86.6 \\
\hline 2.5 & 0.25 & 89.2 \\
\hline 5 & 0.25 & 93.5 \\
\hline 5 & 0.5 & 89.1 \\
\hline 5 & 1.25 & 86.7 \\
\hline 5 & 2.5 & 84.7 \\
\hline 8 & 0.25 & 96.5 \\
\hline & 0.25 & 93.8 \\
\hline binding coefficient $\left(\mathbf{M}^{-1}\right)$ & 2000 & $R^{2}=0.99$ \\
\hline
\end{tabular}

${ }^{a}$ The standard deviations obtained for SFS bound to micelles range between 0.2 and $2 \%$.

Table 2. SFS Speciation and Adsorption in the Presence of $5 \mathrm{mM}$ ODTMA and Different Clay Concentrations

\begin{tabular}{ccccccc}
\hline $\begin{array}{c}\text { clay added } \\
(\mathrm{g} / \mathrm{L})\end{array}$ & $\begin{array}{c}\text { ODTMA } \\
\text { added (mM) }\end{array}$ & $\begin{array}{c}\text { SFS added } \\
(\mathrm{mM})\end{array}$ & $\begin{array}{c}\text { SFS adsorbed } \\
\text { on clay (\%) }\end{array}$ & $\begin{array}{c}\text { SFS bound to } \\
\text { micelles }(\%)^{a}\end{array}$ & $\begin{array}{c}\text { SFS in } \\
\text { solution }(\%)^{a}\end{array}$ \\
\hline 0 & in & 5 & 0.25 & & 93.5 & 6.5 \\
2.5 & in & 5 & 0.25 & 81.5 & 14.1 & 4.4 \\
5 & in & 5 & 0.25 & 97.7 & 0.3 & 2.0 \\
10 & in & 5 & 0.25 & 86.5 & 0.3 & 13.2 \\
2.5 & out & 5 & 0.25 & 1.7 & 93.7 & 4.6 \\
5 & out & 5 & 0.25 & 1.1 & 94.7 & 4.2
\end{tabular}
$3 \%$.

${ }^{a}$ The standard deviations obtained for SFS speciation range between 0.1 and

was determined by measuring its concentration inside and outside the bags (Table 1).

As expected, at concentrations below the critical micelle concentration (CMC), e.g., $0.1 \mathrm{mM}$ ODTMA, no reduction in the solution concentration of SFS was observed. At added concentrations above the CMC, 2.5-10 mM ODTMA, 84.7$96.5 \%$ of the added SFS bound to the micelles. Adding increasing concentrations of SFS $(0.25-2.5 \mathrm{mM})$ to $5 \mathrm{mM}$ of ODTMA resulted in a small decrease in the percent of SFS bound to micelles. The percent of SFS bound to micelles increased as the concentration of ODTMA increased.

The adsorption of neutral molecules on colloidal particles, e.g., clay minerals can be described by the Langmuir (or Scatchard) equation (19). We used this model to evaluate the affinity of the herbicide to the micelles assuming each ODTMA molecule can mostly bind one herbicide molecule. The results (Table 1) indicated that the Langmuir equation can yield good simulation of the experimental percents of SFS bound $\left(R^{2}=\right.$ 0.99 and $\left.\mathrm{RMSE}=1.3 \times 10^{-5} \mathrm{M}\right)$. The values of binding coefficients provide a convenient scale for comparison, rather than absolute values of the changes of the free energy upon adsorption (19). The binding coefficient calculated, $2000 \mathrm{M}^{-1}$, is four times higher than that calculated for SFM, indicating that SFS has a higher affinity to the micelles (17).

SFS Speciation and Adsorption by the Micelle-Clay Complex. Adding $2.5 \mathrm{mM}$ ODTMA and $0.25 \mathrm{mM}$ SFS with increasing clay concentrations (clay added inside the dialysis bag) resulted in increased adsorption of SFS up to a clay concentration of $5 \mathrm{~g} / \mathrm{L}$. However, at a higher clay concentration $(10 \mathrm{~g} / \mathrm{L})$ there was a decrease in the percent of SFS adsorbed and a significant increase in the percent of SFS in solution (Table 2). This trend was also found for SFM adsorption on montmorillonite via its incorporation in micelles (17). The high clay concentration relative to that of ODTMA promoted monomer adsorption and, due to monomer-micelle equilibrium, micelles decomposed, releasing SFS to the solution. 
Table 3. SFS Adsorption on a Micelle-Clay Complex at Different Herbicide Concentrations

\begin{tabular}{cccccc}
\hline $\begin{array}{c}\text { clay } \\
(\mathrm{g} / \mathrm{L})\end{array}$ & $\begin{array}{c}\text { ODTMA } \\
(\mathrm{mM})\end{array}$ & $\begin{array}{c}\text { SFS } \\
(\mathrm{mM})\end{array}$ & $\begin{array}{c}\text { SFS } \\
\text { adsorbed (\%) }\end{array}$ & $\begin{array}{c}\text { formulation } \\
\text { notation }\end{array}$ & $\begin{array}{c}\text { active } \\
\text { ingredient (\%) }\end{array}$ \\
\hline 5 & & 0.25 & 0 & & \\
5 & 5 & 0.05 & 98.9 & $5 / 5 / 0.05$ & 0.35 \\
5 & 5 & 0.25 & 98.3 & $5 / 5 / 0.25$ & 1.8 \\
5 & 5 & 0.5 & 97.0 & $5 / 5 / 0.5$ & 3.5 \\
5 & 5 & 1 & 96.8 & $5 / 5 / 1$ & 7.2
\end{tabular}

\footnotetext{
${ }^{a}$ The standard deviations obtained for SFS adsorption range between 0 and $0.1 \%$.
}

Table 4. Fluorescence Intensity of ODTMA-Clay Complexes and of the Supernatants

\begin{tabular}{|c|c|c|c|c|}
\hline $\begin{array}{l}\text { sample added } \\
\text { ODTMA } \\
(\mathrm{mM}) / \text { clay }(\mathrm{g} / \mathrm{L})\end{array}$ & $5 / 3$ & $2.5 / 3$ & $2.5 / 5$ & $2.5 / 10$ \\
\hline ODTMA adsorbed (\%) & 66 & 89 & 94 & 100 \\
\hline sample & \multicolumn{4}{|c|}{ fluorescence intensity } \\
\hline $\begin{array}{l}\text { ODTMA-N-NBD-PE } \\
\text { adsorbed on clay }{ }^{a}\end{array}$ & 13.8 & 31.1 & 23.1 & 17.0 \\
\hline $\begin{array}{l}\text { supernatant }{ }^{a} \\
\text { supernatant }^{a}+\text { Triton } X\end{array}$ & $\begin{array}{r}4.6 \\
55.0\end{array}$ & $\begin{array}{l}0.5 \\
3.2\end{array}$ & $\begin{array}{l}1.3 \\
5.0\end{array}$ & $\begin{array}{l}1.3 \\
9.8\end{array}$ \\
\hline $\begin{array}{l}\text { ODTMA-N-NBD-PE } \\
\text { adsorbed on RhB-clay }\end{array}$ & 2.9 & 6.0 & 2.4 & 0.9 \\
\hline $\begin{array}{l}\text { ratio between fluorescence } \\
\text { intensities of the complexes } \\
\text { without and with } R h B\end{array}$ & 4.8 & 5.2 & 9.6 & 18.9 \\
\hline
\end{tabular}

\footnotetext{
${ }^{a}$ The values are the fluorescence intensities of the samples after subtracting the intensities of the control samples (without N-NBD-PE).
}

To further test whether the enhanced adsorption of SFS on clay-mineral was due to its incorporation in micelles, the adsorption of SFS on the clay was measured by adding the clay outside the dialysis bag. ODTMA and SFS were added inside the dialysis bags, i.e., the micelles were only present inside the dialysis bag (Table 2). When adding 2.5 and $5 \mathrm{~g} / \mathrm{L}$ clay outside the dialysis bag, only 1.7 and $1.1 \%$ of SFS adsorbed on the clay-mineral, whereas, when the clay was added inside the bag, 81.5 and $97.7 \%$ of SFS adsorbed, respectively. It is clear that when the micelles had access to the clay (clay added inside), a much higher percentage of SFS adsorbed, indicating that SFS bound to ODTMA micelles increases its adsorption on the claymineral.

Understanding SFS speciation in the SFS-micelle-clay system by using dialysis bag experiments enabled to choose SFS, ODTMA, and clay concentrations that would yield a large adsorbed fraction of SFS. SFS adsorption was measured at concentrations varying from 0.05 to $1 \mathrm{mM}$ in the presence of 5 mM ODTMA and $5 \mathrm{~g}$ clay/L (Table 3). SFS did not adsorb on the clay directly (without adding ODTMA). It adsorbed at a very high level when $5 \mathrm{mM}$ ODTMA was added (96.8-98.9\%). A negligible decrease in the adsorbed amounts of SFS occurred upon increasing the concentration of the added SFS $(0.25-1$ $\mathrm{mM})$.

Formulation 5/5/0.25 was prepared in four different ways as described in Methods. Remarkably, all procedures gave the same amount of SFS adsorbed (98\%), irrespective of the order of addition of the components. The significance of this outcome will be discussed later.

Fluorescence Measurements. The purpose of these measurements was to provide a visual demonstration for the close

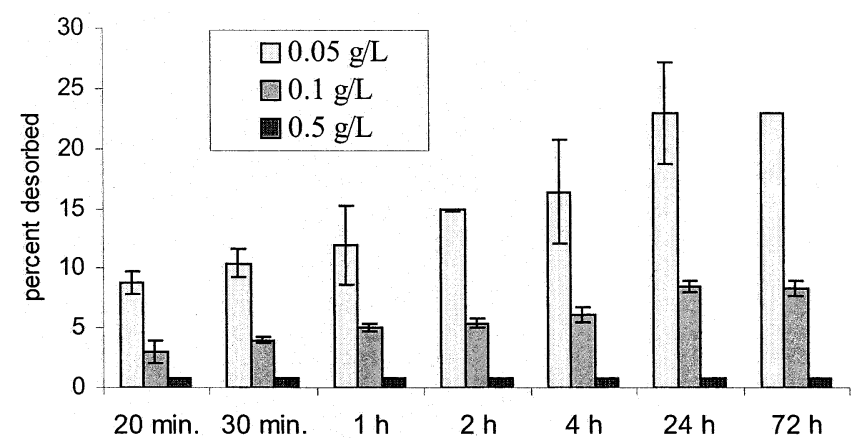

Figure 2. SFS desorption (after 20min-72 h) from a micelle-clay formulation (5/5/1) at different clay concentrations.

approach of micelles to the surface of the clay-mineral and the decomposition of micelles in the presence of excess clay.

An ODTMA solution including N-NBD-PE was placed in a dialysis bag immersed in water. Measuring $\mathrm{N}-\mathrm{NBD}-\mathrm{PE}$ fluorescence intensities inside and outside the dialysis bag showed insignificant exchange of N-NBD-PE during $24 \mathrm{~h}$. The upper limit on the corresponding exchange of N-NBD$\mathrm{PE}$ from micelles to clay outside the dialysis bag reached $1 \%$ at the most during 3 days (results not shown). Part of the exchange may be due to monomer adsorption on the clay when added outside the dialysis bag. The fluorescence intensities of four ODTMA-clay complexes (Table 4) and the supernatants were measured. Each ODTMA-clay complex was prepared with or without both probes $(\mathrm{N}-\mathrm{NBD}-\mathrm{PE}$ and $\mathrm{RhB})$.

The fluorescence intensity measured for the supernatant of the $5 / 3$ complex was much higher than those measured for the complexes with lower ODTMA/clay ratio, and correspondingly the intensity of the $5 / 3$ complex was lower than those obtained with lower ODTMA/clay ratios (Table 4). This is in accord with the result that for the $5 / 3$ sample a higher percent of ODTMA remained as micelles in solution and did not adsorb on the clay.

When adding $2.5 \mathrm{mM}$ ODTMA to increasing clay concentrations $(3,5$, and $10 \mathrm{~g} / \mathrm{L})$ the percent of cation adsorbed increased. However, at high clay concentration, relative to that of the cation, monomer adsorption, rather than micelle adsorption, predominates, and due to monomer/micelle equilibrium, micelles decompose (Table 2). The fluorescence intensity of the $2.5 \mathrm{mM}$ ODTMA-N-NBD-clay complexes decreased as the clay concentration increased, whereas the fluorescence intensity of the supernatants increased (Table 4). Due to micelle decomposition, N-NBD-PE was released to the solution, which increased the fluorescence of the supernatant and decreased that of the complex. It is noteworthy that, upon addition of Triton $\mathrm{X}$, the fluorescence of the supernatant (Table 4) was increased 12 -fold in the case of the $3 / 5$ complex, where nonadsorbed micelles were expected, i.e., more than in other cases.

When adsorbing ODTMA-N-NBD-PE on clay-RhB, we observed a decrease in the fluorescence intensity of the complexes (in comparison with the ODTMA-N-NBD-PEclay complexes) due to energy transfer $(20,21)$. All four complexes showed a decrease in the fluorescence when preadsorbing $\mathrm{RhB}$ on the clay. The fluorescence intensity of complex 2.5/3 decreased 5-fold, whereas that of complex 2.5/10 decreased 19-fold, in accord with the increase in the amounts of the acceptor. When decreasing the RhB load on the clay of the 2.5/ 10 complex, from 2.5 to 1 and to $0.5 \%$ of the CEC, the efficiency of the energy transfer decreased as the amount of the acceptor decreased (results not shown). 


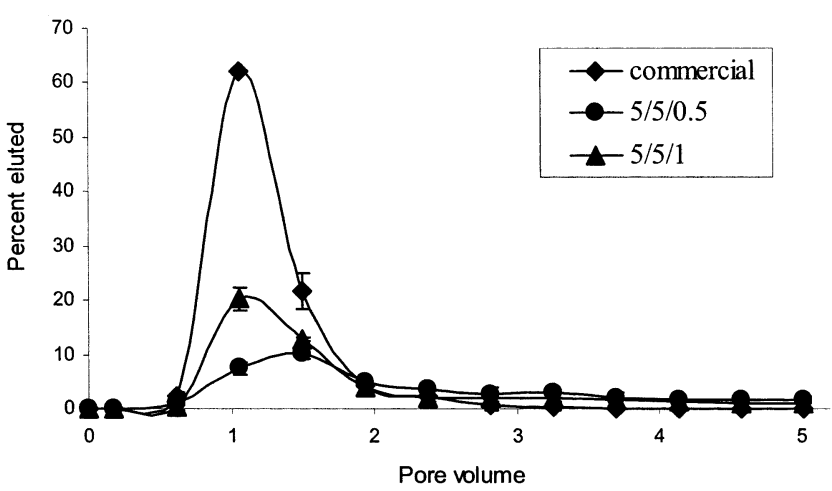

Figure 3. Elution curve of SFS in soil columns sprayed with the commercial, 5/5/0.5, and 5/5/1 formulations.

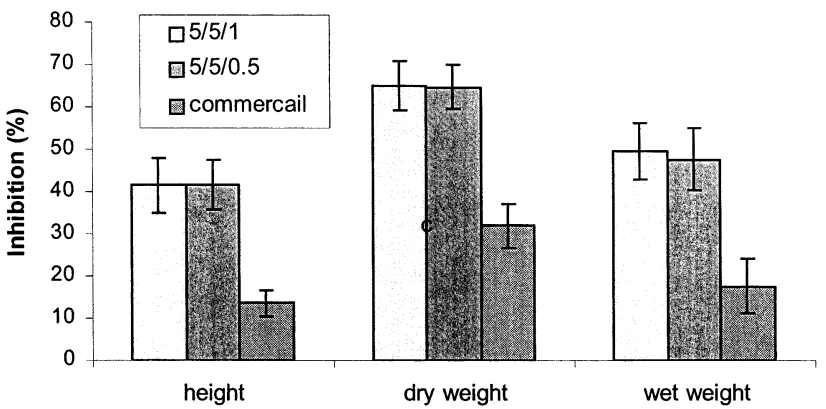

Figure 4. Inhibition of shoot height (\%), dry weight, and wet weight of foxtail in soil columns sprayed with the commercial, $5 / 5 / 0.5$, and $5 / 5 / 1$ SFS formulations.

The fluorescence measurements reinforced previous (17) and current results that an increase in the clay/ODTMA ratio results in micelle decomposition and enhanced monomer adsorption. The energy transfer observed indicates small distances between the micelles and the clay in the micelle-clay complexes (21).

As we have pointed out, the contribution to this energy transfer from exchange of the probe from the micelles to the clay was minimal, approximately $1 \%$. Furthermore, the results in Table $\mathbf{4}$ indicate a maximum in the fluorescence intensity of the $2.5 / 3$ complex, i.e., under conditions of maximal adsorption of ODTMA micelles on the clay. Hence, the fluorescence results give further support to the intimate contact between ODTMA micelles and montmorillonite platelets, which was previously (17) deduced from electron microscopy.

SFS Desorption from SFS-Micelle-Clay Formulations. SFS release to water from a micelle-clay formulation at different concentrations was measured at several times between $20 \mathrm{~min}$ and $72 \mathrm{~h}$ (Figure 2). The desorption of SFS from formulation 5/5/1 reached a maximum value of $23 \%$ at the low clay concentration. As expected, the percent of SFS desorbed decreased as the concentration of the formulation in the solution increased $(0.05-0.5 \mathrm{~g} / \mathrm{L})$. The concentration of SFS desorbed at a clay concentration of $0.5 \mathrm{~g} / \mathrm{L}$ was very low, at the HPLC detection limit $(0.1 \mathrm{ppm})$. The release of the adsorbed SFS from formulation $5 / 5 / 0.5(0.1 \mathrm{~g} / \mathrm{L}$ clay, $3.5 \%$ ai) after $72 \mathrm{~h}$ was $5 \%$, whereas $8.4 \%$ was released from formulation $5 / 5 / 1$, due to its higher content of the active ingredient (7.2\% ai).

The release of SFS at the very low formulation concentrations $(0.1-0.05 \mathrm{~g} / \mathrm{L})$ may simulate its concentration at the top of the soil, following irrigation. At these concentrations, the percent of SFS desorbed increased with time but remained low, reaching equilibration after $24 \mathrm{~h}$, which indicates slow release. Consequently, micelle-clay formulations have a potential to yield slow release of SFS.

Leaching Studies. Thin Soil Layers in Funnels-Analytical Test. After one irrigation (equivalent to $5 \mathrm{~mm}$ of rain), $78 \%$ of SFS from the commercial formulation leached through the thin soil layer, whereas only $0.5 \%$ of SFS leached from the micelleclay formulation (5/5/0.5). After 10 irrigations $(50 \mathrm{~mm}), 100 \%$ of SFS leached from the commercial formulation, and only $4 \%$ leached from the micelle-clay formulation. These results clearly indicate the potential of the micelle-clay formulation of SFS to yield slow release and reduced leaching.

Soil Columns-Analytical Test. Figure 3 shows the breakthrough curves of the commercial and clay-based formulations of SFS. When adding 1 pore volume (the point of maximum elution), which is equivalent to $80 \mathrm{~mm}$ of rain, the cumulative amounts of SFS eluted were 64 and $21 \%$ for the commercial and the 5/5/1 formulations, respectively. This indicates that the micelle-clay formulation of SFS can reduce its leaching 3-fold.

The total recovery of SFS from the commercial formulation amounts to $93.6 \pm 5.4 \%$, which is in agreement with previous

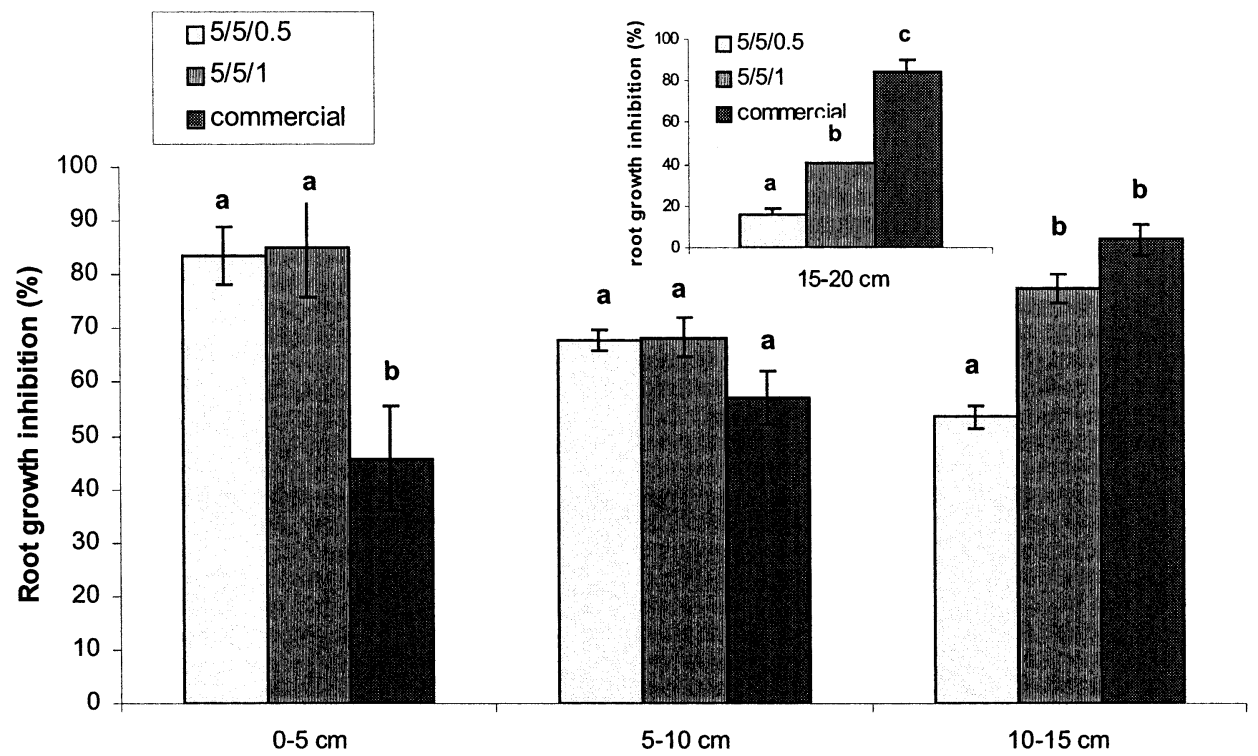

Figure 5. Root growth inhibition (\%) of a test plant (sorghum) as a function of the depth of soil columns sprayed with the SFS commercial formulation, formulation 5/5/0.5, or formulation 5/5/1. The inset indicates the root growth inhibition (\%) at a depth of $15-20 \mathrm{~cm}$, where the soil was diluted 10 times. 
studies, indicating low adsorption of sulfonylureas in most agricultural soils due to their presence as anionic forms $(\mathrm{pH}>6$ ) (22). Even after intensive irrigation ( 5 pore volumes, which is equivalent to $400 \mathrm{~mm}$ of rain) the total leaching of SFS from the micelle-clay formulations reached $40 \pm 3.5$ and $48.0 \pm$ $6.5 \%$ for the $5 / 5 / 0.5$ and $5 / 5 / 1$ formulations, respectively. The lower percent of leaching for the 5/5/0.5 formulation corresponds to its lower content of active ingredient. The peak for the 5/5/ 0.5 formulation is shifted to the right, indicating that the release from this formulation was not only less but also slower than the release from the 5/5/1 formulation and the commercial one. Thus, these results show that the micelle-clay formulations of SFS can yield a significant reduction in its leaching, in accord with the results of release to water and those of the funnel experiment.

Plant Bioassay. Two micelle-clay formulations of SFS, 5/5/ $0.5,5 / 5 / 1$ (Table 3), and the commercial formulation were tested using a plant bioassay in soil columns, and the results were compared to those of control columns sprayed with water. Two columns of each treatment were sown with the test plant green foxtail. The shoot growth and dry and wet weights were measured (Figure 4).

The main requirements for an efficient formulation are high biological activity at the root zone and little activity at depths where no biological activity is needed. The commercial formulation does not fulfill these basic requirements, as shown in Figure 4 and as can be seen by the fact that only 14\% shoot growth inhibition was achieved. The micelle-clay formulations yielded $40 \%$ shoot growth inhibition, about 3-fold the activity of the commercial formulation. The inhibition percents of the shoot dry weight were 65 and $32 \%$ for the micelle-clay and commercial formulations, respectively. These results strongly emphasize the agricultural advantage of the new micelle-clay formulations.

To check the leaching of the different formulations in the soil columns, Petri dishes were filled with the soil from different depths, sorghum seeds were placed in each Petri dish, and the root length was measured. The percent of root growth inhibition was calculated by comparing the root length of each sample to the average length of the roots from the control columns.

Only $46 \%$ root growth inhibition was detected at the top 5 $\mathrm{cm}$ of the column sprayed with the commercial formulation, and the inhibition increased with the depth. At a depth of 15$20 \mathrm{~cm}, 84 \%$ inhibition was observed, and when taking into account that the soil, at this depth, was diluted 10 times, the herbicide's activity at this depth would have been even higher (Figure 5). This trend of herbicide distribution throughout the soil depth is certainly undesired.

On the other hand, a high percent of root growth inhibition, $84-85 \%$, was measured at the top $5 \mathrm{~cm}$ of soil when SFS was applied as a micelle-clay formulation, $5 / 5 / 0.5$ and $5 / 5 / 1$. The columns sprayed with formulation $5 / 5 / 0.5$ showed a sharp decrease in the percent of root growth inhibition with depth, and at a depth of 15-20 cm, the inhibition was 5-fold less than that found for the columns sprayed with the commercial formulation (Figure 5). Formulation 5/5/1 gave less leaching (2-fold) at a depth of $15-20 \mathrm{~cm}$ in comparison with the commercial one. This indicates that applying the micelle-clay formulation can reduce herbicide leaching to harmful depths. The higher leaching found in the case of formulation $5 / 5 / 1$ in comparison with formulation $5 / 5 / 0.5$ is due to the higher percent of active ingredient in the formulation, which leads to higher desorption, as was found in the release experiments.

Applying the newly designed micelle-clay formulations improved the biological activity at the root zone 2-fold and decreased the leaching 5-fold, which demonstrates their environmental, agricultural, and economical benefit.

\section{CONCLUDING REMARKS}

The results indicate that the micelle-montmorillonite complexes have different characteristics from those of the monomerclay complex. The micelle-clay system can adsorb most of the anionic herbicide added, whereas the monomer-clay complex is not suitable for SFS (or SFM (17)) adsorption, unlike its suitability for adsorption of hydrophobic herbicides $(18,19)$. Differences between the two complexes were also elucidated by fluorescence studies. Table 4 shows that the 2.5/3 complex formed from $2.5 \mathrm{mM}$ ODTMA and $3 \mathrm{~g} / \mathrm{L}$ clay ( $89 \%$ of the cation adsorbed) gave larger fluorescence intensity of N-NBDPE initially incorporated in ODTMA micelles than the 2.5/10 complex (complete cation adsorption), in accord with the outcome that, in the latter case, a large fraction of micelles decomposes to monomers.

We have pointed out that the order of addition of components, i.e., SFS, ODTMA, and clay yielded the same large fracton of adsorbed SFS (98\%) in the case of the $0.25 / 5 / 5$ formulation (Table 3). Thus, adding SFS to the ODTMA-clay suspension after $24 \mathrm{~h}$ gave the same outcome as incorporating it first in the ODTMA micelles. This result, together with the result that adsorption of SFS was minimal on the monomer-clay complex implies that the integrity of the micelles was preserved for a long period and that SFS may have penetrated into aggregates of ODTMA-clay particles. This finding is also significant for future possible applications of the micelle-clay system in removal of anionic organic pollutants from water. Since $98 \%$ of the added SFS was removed from water $(\mathrm{pH} 7.4)$ in a $0.5 \%$ clay suspension, it can be anticipated that essentially complete removal from water can be achieved for typical lower concentrations of anionic pollutants.

The results of the analytical tests, thin soil layers in funnels and soil columns, demonstrate significantly reduced leaching of SFS from the slow-release micelle-clay formulations, in comparison with that from the commercial formulation. Hence, the new formulations are advantageous from the environmental point of view. The results from the plant bioassay demonstrate that the new formulations have severalfold enhanced biological activity and are advantageous from the agricultural and economical points of view. These two aspects are connected, because the slow release and reduced leaching enable the attaining of relatively larger herbicide concentrations in the root zone, where its activity is more effective.

\section{ABBREVIATIONS USED}

SFS, sulfosulfuron; SFM, sulfometuron; ODTMA, octadecyltrimethylammonium; CMC, critical micelle concentration; CEC, cation exchange capacity; RhB, Rhodamin B; N-NBD$\mathrm{PE}$, 1,2-dipalmitoyl-sn-glycero-3-phosphoethanolamine- $\mathrm{N}$-(7nitro-2-1,3-benzoxadiazol-4-yl).

\section{LITERATURE CITED}

(1) Ahrens, H. W. Herbicide Handbook, 7th ed.; Weed Science Society of America: Champaign, IL, 1994.

(2) Veeh, R. H.; Inskeep, W. P.; Roe, F. L.; Ferguson, A. H. Transport of chlorsulfuron through soil columns. J. Environ. Qual. 1994, 23, 542-549.

(3) Stork, P. R. Field leaching and degradation of soil applied herbicides in a gradationally textured alkaline soil: chlorsulfuron and triasulfuron. Aust. J. Agric. Res. 1995, 46, 1445-1458. 
(4) Pool, C. F.; Du-Toit, D. Leaching depth of imazamethabenz methyl and chlorsulfuron and metsulfuron methyl in different soils. Applied Plant Sci. 1995, 9, 43-47.

(5) Sarmah, A. K.; Kookana, R. S.; Alston, A. M. Fate and behavior of trisulfusulfuron, metsulfuron-methyl, and chlorsulfuron in Australian soil environment: a review. Aust. J. Agric. Res. 1998 , 49, 775-790.

(6) Black, I. D.; Pederson R. N.; Flynn, A.; Moerkerk, M.; Dyson, C. B.; Kookana, R.; Wilhelm, N. Mobility and persistence of three sulfonylurea herbicides in alkaline cropping soils of southeastern Australia. Aust. J. Exp. Agric. 1999, 39, 465-472.

(7) El Nahhal, Y.; Nir, S.; Serban, C.; Rabinovitch O.; Rubin, B. Montmorillonite-Phenyltrimethylammonium Yields Environmentally Improved Formulations of Hydrophobic Herbicides. J. Agric. Food Chem. 2000, 48, 4791-4801.

(8) Theng, B. K. G. The chemistry of clay-organic reactions; Wiley: New York, 1974.

(9) Lagaly, G. Layer charge heterogeneity in vermiculites. Clays Clay Miner. 1982, 30, 215-222.

(10) Jaynes, W. F.; Boyd, S. A. Clay mineral type and organic compound sorption by hexadecyltrimethylammonium-exchanged clays. Soil Sci. Soc. Am. J. 1991, 55, 43-48.

(11) Zhang, Z.; Sparks, D. L.; Scrivner, N. C. Sorption and desorption of quaternary amine cations on clays. Environ. Sci. Technol. 1993, 27, 1625-1631.

(12) Xu, S.; Boyd, S. A. Cationic surfactant sorption to a vermiculitic subsoil via hydrophobic bonding. Environ. Sci. Technol. 1995, 29, 312-320.

(13) Park, J.; Jaffe, P. R. Partition of three nonionic organic compounds between adsorbed surfactants, micelles, and water. Environ. Sci. Technol. 1993, 27, 2559-2585.

(14) Sun, S.; Inskeep, W. P.; Boyd, S. A. Sorption of nonionic organic compounds in soil-water systems contaning a micelle-forming surfactant. Environ. Sci. Technol. 1995, 29, 903-913.

(15) Porras-Rodriguez, M.; Talens-Alesson, F. I. Removal of 2,4Dichlorophenoyacetic acid from water by adsorptive micellar flocculation. Environ. Sci. Technol. 1999, 33, 3206-3209.
(16) Wang, Y.; Banziger, J.; Dubin, P. L.; Fillippelli, G.; Nuraje, N. Adsorptive partitioning of an organic compound onto polyelectrolyte-immobilized micelles on porous glass and sand. Environ. Sci. Technol. 2001, 35, 2608-2611.

(17) Mishael, Y. G.; Undabeytia T.; Rytwo, G.; PapahadjopoulosSternberg B.; Rubin B.; Nir, S. Sulfometuron incorporation in cationic micelles adsorbed on montmorillonite. J. Agric. Food Chem. 2002, 50, 2864-2869.

(18) El Nahhal, Y.; Nir, S.; Polubesova, T.; Margulies, L.; Rubin, B. Leaching, phytotoxicity, and weed control of new formulations of alachlor. J. Agric. Food Chem. 1998, 46, 3305-3313.

(19) Nir, S.; Undabeytia, T.; Yaron Marcovich, D.; El Nahhal, Y.; Polubesova, T.; Serban, C.; Rytwo, G.; Lagaly, G.; Rubin, B. Optimization of adsorption of hydrophobic herbicides on montmorillonite preadsorbed by monovalent organic cations: interaction between phenyl rings. Environ. Sci. Technol. 2000, 34, 1269-1274.

(20) Struck, D. K.; Hoekstra, D.; Pagano, R. E. Use of resonance energy transfer to monitor membrane fusion. Biochemistry 1981, 20, 4093-4099

(21) Forster, T. Z. Naturforsch. 1949, 4A, 321-327.

(22) Harvey, J.; Dulka, J.; Anderson, J. J. Properties of sulfometuron methyl affecting its environmental fate: aqueous hydrolysis and photolysis, mobility and adsorption on soils, and bioaccumulation. J. Agric. Food Chem. 1985, 33, 590-596.

Received for review November 21, 2002. Revised manuscript received February 2, 2003. Accepted February 8, 2003. Supported in part by The Hebrew University of Jerusalem through a grant from The Wolfson Foundation for Scientific Research, Matching-Bergman, Grant 1317 from Israeli Ministry of Science, Culture and Sport and by Grant G-641-106.8/1999 from G.I.F., the German-Israeli Foundation for Research and Development. Dr. Undabeytia acknowledges the Spanish government for a research contract, Project N. REN2000-1540 TECNO.

JF0261497 